\title{
Monitoring the critically endangered Clanwilliam cedar with freely available Google Earth imagery
}

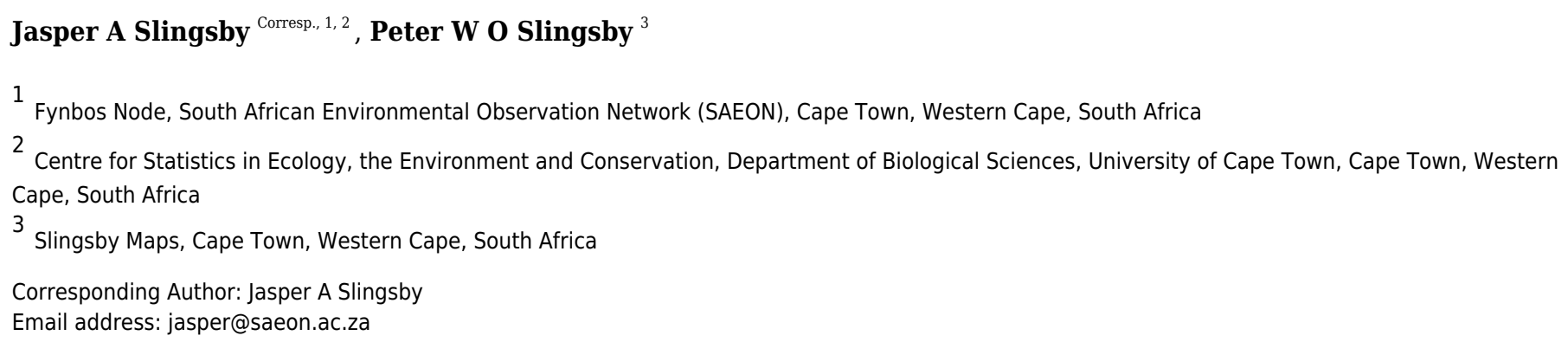

Monitoring of species and populations is essential for biodiversity observation and reporting at local, national and global scales, but can be an exceedingly difficult task for many, if not most, species. We tested the viability of using Google Earth ${ }^{\mathrm{TM}}$ imagery to manually map and monitor all individuals of the critically endangered Clanwilliam cedar, Widdringtonia wallichii Endl. ex Carrière, across its global native distribution; the remote and rugged Cederberg mountains. Comparison with sampling from field surveys reveals this to be a highly efficient and effective method for mapping healthy adult tree localities, but it fails to detect small or unhealthy individuals with green canopies $<4 \mathrm{~m}^{2}$, or discern the number of individuals in clumps. This approach is clearly viable as a monitoring tool for this species and, with the rapid progress being made in machine learning approaches and satellite technology, will only become easier and more feasible for a greater number of species in the near future. Sadly, our field surveys revealed that the number of trees that have recently died (dead leaves still present) outnumbered live trees by a ratio of 2:1. 
1 Monitoring the critically endangered Clanwilliam cedar

2 with freely available Google Earth imagery

3

4 Jasper A. Slingsby ${ }^{1,2 *}$, Peter W. O. Slingsby ${ }^{3}$

5

$6{ }^{1}$ Fynbos Node, South African Environmental Observation Network (SAEON), Cape Town,

$7 \quad$ Western Cape, South Africa, jasper@saeon.ac.za

8

$9 \quad{ }^{2}$ Centre for Statistics in Ecology, Environment and Conservation, Department of Biological

10 Sciences, University of Cape Town, Cape Town, Western Cape, South Africa

11

12 3Slingsby Maps, Cape Town, Western Cape,, South Africa, slingsby@icon.co.za

$14 *$ corresponding author

15 


\section{Abstract}

18 Monitoring of species and populations is essential for biodiversity observation and reporting at

19 local, national and global scales, but can be an exceedingly difficult task for many, if not most, 20 species. We tested the viability of using Google Earth ${ }^{\mathrm{TM}}$ imagery to manually map and monitor

21 all individuals of the critically endangered Clanwilliam cedar, Widdringtonia wallichii Endl. ex

22 Carrière, across its global native distribution; the remote and rugged Cederberg mountains.

23 Comparison with sampling from field surveys reveals this to be a highly efficient and effective

24 method for mapping healthy adult tree localities, but it fails to detect small or unhealthy

25 individuals with green canopies $<4 \mathrm{~m}^{2}$, or discern the number of individuals in clumps. This

26 approach is clearly viable as a monitoring tool for this species and, with the rapid progress being

27 made in machine learning approaches and satellite technology, will only become easier and more

28 feasible for a greater number of species in the near future. Sadly, our field surveys revealed that

29 the number of trees that have recently died (dead leaves still present) outnumbered live trees by a 30 ratio of $2: 1$. 


\section{Introduction}

34 The charismatic Clanwilliam cedar, Widdringtonia wallichii Endl. ex Carrière (routinely referred

35 to by the later homotypic synonym $W$. cedarbergensis Marsh), a narrow endemic within the

36 Cederberg mountains, Fynbos Biome, South Africa ( $\left.32^{\circ} 18^{\prime} \mathrm{S} 19^{\circ} 06^{\prime} \mathrm{E}\right)$, has shown precipitous

37 decline in population numbers over the past two centuries. While there are anecdotes of

38 overexploitation in the early 1800s (Smith, 1955), recent evidence from analysis of repeat

39 photographs suggests that mortality has been exacerbated by anthropogenic climate change,

40 particularly over the past 30 years (White et al., 2016). This is consistent with a global analysis

41 revealing increased climate-induced tree mortality over the past 40 years (Allen et al., 2010),

42 with conifer species being especially vulnerable. With increasing evidence of climate change

43 impacts on South African vegetation (Foden et al., 2007; Slingsby et al., 2017; White et al.,

44 2016), it is key that we improve our ability to detect and track these impacts, both to raise public

45 awareness and to improve our understanding of anticipated environmental change.

While the monitoring of species and populations is one of the six major classes of

47 Essential Biodiversity Variables "required to study, report, and manage biodiversity change"

48 (Pereira et al., 2013), this can be an exceedingly difficult task in rugged and remote landscapes,

49 or where species are difficult to detect. Fortunately, freely available, high resolution satellite

50 imagery is making this more feasible for large organisms such as trees (Visser et al., 2014; Geller

51 et al., 2017). Here we test the viability of using Google Earth ${ }^{\mathrm{TM}}$ imagery to map and monitor all

52 individuals of the Clanwilliam cedar across its global native distribution.

\section{Material \& methods}


56 Tree localities for the entire species' distribution were manually mapped from high-resolution

57 CNES/Airbus satellite imagery available from Google Earth ${ }^{\mathrm{TM}}$ for the year 2013. Trees were

58 identified based on canopy colour, size, shape and shadows, and, where possible, verified with

59 ground photographs from the publicly contributed archives accessible through Google Earth ${ }^{\mathrm{TM}}$

60 and a personal collection of $\sim 19000$ georeferenced images from research for the Cederberg

61 hiking map (Slingsby, 2015). Early tests found that we could not detect dead trees, likely because

62 they cast very little shadow and their stems are mostly white and cannot be discerned from the

63 high cover of white rock in the area. Trees with brown canopies were ignored as they were likely

64 dead and/or other species. For visual identification and mapping, Google Earth ${ }^{\mathrm{TM}}$ scenes were $^{2}$

65 exported to CorelDRAW ${ }^{\circledR}$ (Corel Corporation, 2016), the colour balance adjusted, and trees

66 marked as points in a layer. The tree points layer was then exported as a vector image and

67 georeferenced and converted to Keyhole Markup Language (KML) in ArcGIS 10.2 (ESRI,

68 2011). Minimum horizontal mapping accuracy was established by opening the KML in Google

69 Earth $^{\mathrm{TM}}$ and measuring the distance between 200 mapped points and the trees they represent

70 using the measuring tool. Dense areas were avoided to reduce confusion between target trees.

71 To validate our satellite enumeration approach on the ground, we mapped the GPS

72 location and size class (adult $=$ canopy $>4 \mathrm{~m}^{2}$, sub-adult $=$ canopy $>1$ and $<4 \mathrm{~m}^{2}$, and seedlings $=$

73 canopy $<1 \mathrm{~m}^{2}$ ) of all cedar trees found within three circumscribed field sites across the species'

74 range. We then compared our field survey results with population estimates from our satellite

75 image analysis, exploring the influence of size class on detection from satellite. Since our first

76 site survey revealed that the trees can survive substantial canopy dieback, we also recorded the 
77 size of the live canopy of trees for the two subsequent field sites to explore the effect of live 78 canopy size on detection from satellite.

79

\section{0 \\ Results}

81

We mapped 13419 cedar tree localities (Fig. 1), taking an estimated 200 working hours. None of

83

84

85

86

87

88

92

93

94

95 our 200 sample trees fell more than 20 metres from the mapped point, suggesting a horizontal mapping accuracy $<20 \mathrm{~m}(\sim 1: 24000)$.

Our ground surveys took five days for a team of two to cover $1 / 20000^{\text {th }}$ of the Clanwilliam cedar's range. We found 123 live trees (61 adults, 24 subadults and 38 seedlings), while our satellite approach detected only 21 healthy green canopies in the same area (Fig. 1). Our canopy health data from two of the three field sites revealed that of the 25 live adult trees only 10 had healthy green canopies $>4 \mathrm{~m}^{2}$, while our satellite approach counted 9 trees. Our field survey also revealed 237 dead trees (i.e. a ratio of two dead to every live tree), made up of 109 adults, 82 sub-adults and 46 seedlings, still bearing dead leaves.

\section{Discussion}

5 Our satellite-based approach did very well to provide a near-perfect fine-scale description of the

6 Clanwilliam cedar's distribution, providing a detailed baseline that allows monitoring of future

7 change, and allowing inference of fine-scale habitat preferences that could lead to a better understanding of the species' ecology and causes of its decline. While the satellite image analysis clearly missed smaller individuals and those with unhealthy canopies, and cannot 
100 discern between clumps of trees and single individuals, it provides a very good indication of the

101 locations of adult trees with live canopies. We achieved a horizontal mapping accuracy suitable

102 for most applications, but it could likely be improved if all analyses were performed directly in

103 Google Earth ${ }^{\mathrm{TM}}$ or Geographic Information System (GIS). This would likely require the ability

104 to modify the colour balance of images directly in the software to aid visual detection. With good

105 field estimates of the species' size class distribution and canopy health it would be feasible to

106 provide a relatively accurate estimate of population numbers based on the locality data. Our

107 small field survey and work by White et al. (2016) both suggest that population structure, canopy

108 health, recruitment (presence of seedlings) and mortality (presence of dead stems) are highly

109 varied across the Cederberg, cautioning against extrapolation without sufficient sampling,

110 stratified across environmental gradients and spanning the species' full range.

111 There was no evidence to suggest there were any errors of commission, whereby

112 individuals of other species were mistaken for the Clanwilliam cedar. The most likely species

113 would have been Heeria argentea (Thunb.) Meisn. or Podocarpus elongatus (Aiton) L'Hér. ex

114 Pers., but these were readily distinguishable by differences in canopy colour, shape, shadow and

115 habitat. Omission rates may vary depending on topography and the recent occurrence of fire; but

116 error rates for localities with adult trees or clumps $>4 \mathrm{~m}^{2}$ are likely to be low.

117 This observation method is clearly highly efficient and effective, and has great potential

118 for application to other important plant species worldwide, especially large trees or shrubs that

119 occur in sparse vegetation. Key species in South Africa include the declining Aloidendron

120 dichotomum (Masson) Klopper \& Gideon (Foden et al., 2007), large species in the Proteaceae

121 Juss. (Schurr et al., 2012), or savanna trees. 
While our approach is far cheaper and more time-efficient than an exhaustive (and 123 exhausting!) field survey, the field of image analysis with machine learning approaches is 124 moving incredibly rapidly (Demir et al., 2018) and will greatly reduce the need for and time 125 spent doing manual digitization of individual localities. This, combined with the growing record 126 of satellite and aerial imagery with continually improving spatial and spectral resolution will 127 soon allow for rapid and cost effective monitoring of many species across their global 128 distribution ranges (Geller et al., 2017).

129

130

\section{Acknowledgements}

The authors would like to thank Google for making their imagery freely available. We also thank 133 Amy Slingsby, Glenn Moncrieff, Nicky Allsopp and Abri de Buys for assistance with field work, and Thomas Slingsby for converting the tree layer into Keyhole Markup Language (KML) 135 format.

\section{References}

Allen, C.D., Macalady, A.K., Chenchouni, H., Bachelet, D., McDowell, N., Vennetier, M., Kitzberger, T., Rigling, A., Breshears, D.D., Hogg, E.H. (ted), Gonzalez, P., Fensham, R., Zhang, Z., Castro, J., Demidova, N., Lim, J.-H., Allard, G., Running, S.W., Semerci, A., Cobb, N., 2010. A global overview of drought and heat-induced tree mortality reveals emerging climate change risks for forests. For. Ecol. Manage. 259, 660-684.

143 Corel Corporation, 2016. CorelDRAW.

144 Demir, I., Koperski, K., Lindenbaum, D., Pang, G., Huang, J., Basu, S., Hughes, F., Tuia, D., 
145

146

147

148

149

150

151

152

153

154

155

156

157

158

159

160

161

162

163

164

165

166

167

Raska, R., 2018. Deepglobe 2018: A challenge to parse the earth through satellite images, in: 2018 IEEE/CVF Conference on Computer Vision and Pattern Recognition Workshops (CVPRW). IEEE, pp. 172-17209.

ESRI, 2011. ArcGIS Desktop.

Foden, W., Midgley, G.F., Hughes, G., Bond, W.J., Thuiller, W., Hoffman, M.T., Kaleme, P., Underhill, L.G., Rebelo, A., Hannah, L., 2007. A changing climate is eroding the geographical range of the Namib Desert tree Aloe through population declines and dispersal lags: Namib Desert trees feel the heat of climate change. Diversity and Distributions 13, 645-653.

Geller, G.N., Halpin, P.N., Helmuth, B., Hestir, E.L., Skidmore, A., Abrams, M.J., Aguirre, N., Blair, M., Botha, E., Colloff, M., Dawson, T., Franklin, J., Horning, N., James, C., Magnusson, W., Santos, M.J., Schill, S.R., Williams, K., 2017. Remote Sensing for Biodiversity, in: Walters, M., Scholes, R.J. (Eds.), The GEO Handbook on Biodiversity Observation Networks. Springer International Publishing, Cham, pp. 187-210.

Jarvis, A., Reuter, H.I., Nelson, A., Guevara, E., 2008. Hole-filled seamless SRTM data V4, International Centre for Tropical Agriculture (CIAT), available from http://srtm.csi.cgiar.org Pereira, H.M., Ferrier, S., Walters, M., Geller, G.N., Jongman, R.H.G., Scholes, R.J., Bruford, M.W., Brummitt, N., Butchart, S.H.M., Cardoso, A.C., Coops, N.C., Dulloo, E., Faith, D.P., Freyhof, J., Gregory, R.D., Heip, C., Höft, R., Hurtt, G., Jetz, W., Karp, D.S., McGeoch, M.A., Obura, D., Onoda, Y., Pettorelli, N., Reyers, B., Sayre, R., Scharlemann, J.P.W., Stuart, S.N., Turak, E., Walpole, M., Wegmann, M., 2013. Essential biodiversity variables. Science 339, 277-278.

Schurr, F.M., Esler, K.J., Slingsby, J.A., Allsopp, N., 2012. Fynbos Proteaceae as model 
organisms for biodiversity research and conservation. S. Afr. J. Sci. 108, 12-16.

169 Slingsby, J.A., Merow, C., Aiello-Lammens, M., Allsopp, N., Hall, S., Kilroy Mollmann, H., 170 Turner, R., Wilson, A.M., Silander, J.A., Jr, 2017. Intensifying postfire weather and 171 biological invasion drive species loss in a Mediterranean-type biodiversity hotspot. Proc. Natl. Acad. Sci. U. S. A. 114, 4697-4702.

173 Slingsby, P., 2015. Hike the Cederberg Map, 2nd Edition.

174 Smith, C.A., 1955. Early 19th Century records of the Clanwilliam cedar (Widdringtonia 175 juniperoides End1.). Journal of the South African Forestry Association 25, 58-65. 176 Visser, V., Langdon, B., Pauchard, A., Richardson, D.M. 2014. Unlocking the potential of 177 Google Earth as a tool in invasion science. Biol. Invasions 16, 513-534.

178 White, J.D.M., Jack, S.L., Hoffman, M.T., Puttick, J., Bonora, D., Visser, V., February, E.C., 179 2016. Collapse of an iconic conifer: long-term changes in the demography of Widdringtonia 180 cedarbergensis using repeat photography. BMC Ecol. 16, 53. 


\section{Figure 1}

Clanwilliam cedar size class distribution and tree localities

(A) Barplot of trees of different size classes ( $\mathrm{A}=$ adult; canopy $>4 \mathrm{~m}^{2}, \mathrm{SA}=$ sub-adult, canopy $>1$ and $<4 \mathrm{~m}^{2}, \mathrm{~S}=$ seedling; canopy $<1 \mathrm{~m}^{2}$ ) within our field sites observed on the ground or using satellite imagery from Google Earth ${ }^{\mathrm{TM}}$. (B) Map of Clanwilliam cedar tree localities (black points) mapped from 2013 Google Earth ${ }^{\mathrm{TM}}$ imagery showing the Cederberg Wilderness Area boundary (dashed line), and field survey sites (white circles with black centre). Terrain image generated from the Shuttle Radar Topography Mission (SRTM) 90m digital elevation model (Jarvis et al. 2008).

A

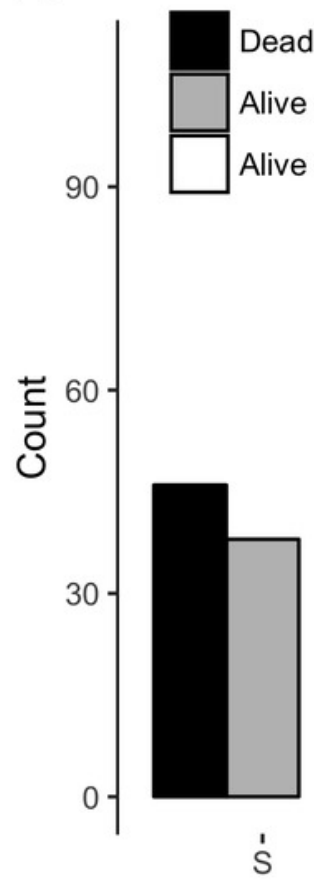



Size class
B

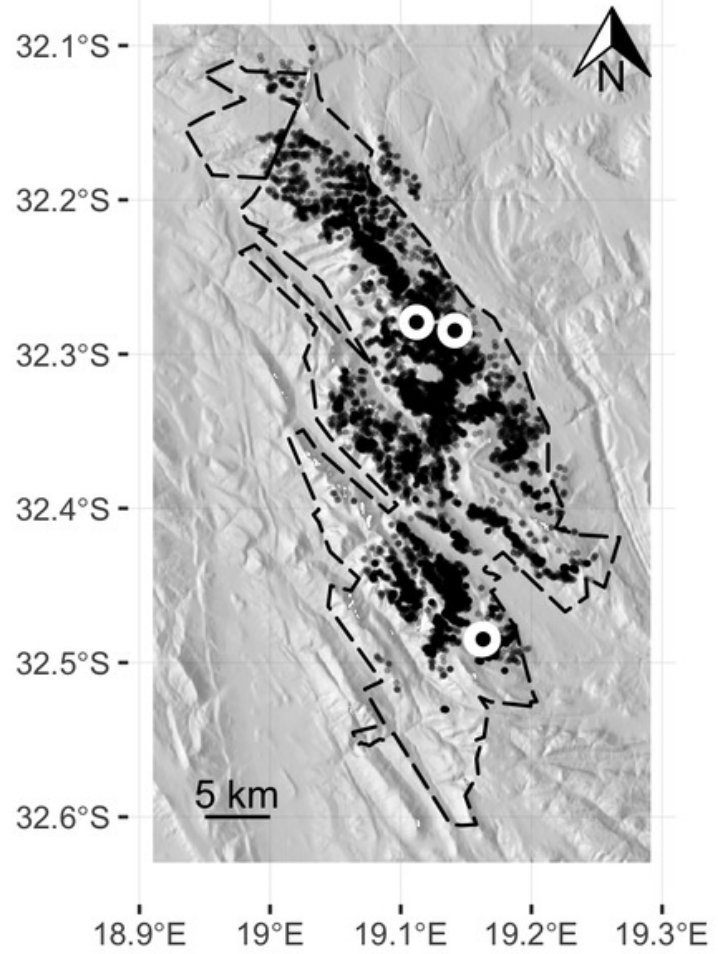

